\title{
Oral Health Behaviors in a Sample of Portuguese Adolescents: An Educational Issue
}

\author{
Nélio Veiga ${ }^{1,2,3,4}$, Carlos Pereira2 ${ }^{2}$, Paula Ferreira4, ${ }^{4}$ Ilidio J. Correia ${ }^{3}$ \\ ${ }^{1}$ Health Sciences Department, Portuguese Catholic University, Viseu, Portugal \\ ${ }^{2} \mathrm{CI} \&$ DETS-Polytechnic Institute of Viseu, Viseu, Portugal \\ ${ }^{3}$ Health Sciences Research Centre, Health Sciences Faculty, Beira Interior University, Covilhã, Portugal \\ ${ }^{4}$ CIEPQPF, Chemical Engineering Department, University of Coimbra, Coimbra, Portugal \\ Email: nelioveiga@gmail.com
}

Received 20 May 2014; revised 2 July 2014; accepted 16 July 2014

Copyright (C) 2014 by authors and Scientific Research Publishing Inc.

This work is licensed under the Creative Commons Attribution International License (CC BY).

http://creativecommons.org/licenses/by/4.0/

(c) (i) Open Access

\begin{abstract}
Introduction: Oral health education is an important issue that should be given to children and adolescents, allowing the acquisition of correct oral health behaviors. The objective of this study was to determine the prevalence of oral health behaviors among a sample of portuguese adolescents and verify the association with socio-demographic factors, in order to analyze the main needs related with oral health education to improve oral health status among adolescents. Methods: A cross-sectional study was designed with a sample of 447 adolescents aged 12 to 19 years old, attending a public school in Sátão, Portugal. A self-administered questionnaire was applied questioning about socio-demographic factors and oral health behaviors to each adolescent in the classroom. Prevalence was expressed in proportions and crude odds ratio (OR) with $\mathbf{9 5 \%}$ confidence intervals (CI) were used to measure the strength of association between oral health behaviors and socio-demographic factors. Results: The prevalence of tooth brushing (twice-a-day or more) was $\mathbf{9 0 . 6 \%}$. Five point eight percent of adolescents reported daily flossing, more frequent among female gender (female, $\mathrm{OR}=2.03,95 \% \mathrm{CI}=(1.35$ to 3.05$)$ ) and adolescents older than 15 years $(>15$ years, $\mathrm{OR}=1.90,95 \% \mathrm{CI}=(1.24$ to 2.92$))$. Sixty-seven percent had at least one dental appointment in the previous twelve months. The prevalence of dental appointments was associated with the father's professional situation (unemployed, $\mathrm{OR}=0.33,95 \% \mathrm{CI}=(0.17$ to 0.65$)$ ) and crowding index $(>1,0 \mathrm{R}=0.4,95 \% \mathrm{CI}=(0.16$ to 0.98$))$. Thirty-two point nine percent of adolescents referred having at least one episode of dental pain during their lives. Conclusion: Considering the results of the present study that show the need of improvement of some aspects related with oral health among adolescents, oral health community programs and primary preventive strategies, such as improvement of oral health education in schools should be considered in order to reduce the risk level of oral diseases and develop better oral health behaviors.
\end{abstract}




\title{
Keywords
}

\author{
Oral Health, Education, Oral Hygiene, Socio-Demographic Factors, Adolescents, Primary \\ Prevention
}

\section{Introduction}

Oral health is defined by the World Health Organization (WHO) "as being free of chronic mouth and facial pain, oral and throat cancer, oral sores, birth defects such as cleft lip and palate, periodontal (gum) disease, tooth decay and tooth loss, and other diseases and disorders that affect the mouth and oral cavity" [1].

Nowadays, dental caries and periodontal diseases are two of the most prevalent diseases worldwide, and, simultaneously, easily preventable with simple primary prevention methods [1]. They are the main cause of dental loss and therefore are considered an important public health issue that affects children, adolescents, adults and the elder. Oral diseases can also be associated with other diseases and may cause serious repercussions in the quality-of-life of the population [1] [2].

Some developed countries have assisted to a decrease of the incidence and prevalence of oral diseases that is explained by the implementation of primary prevention measures at a community level. On the other hand, the prevalence of oral diseases is still high in some countries, mainly among developing countries, where dental caries and periodontal diseases affect all ages in an epidemic matter, and are highly associated with morbidity [3].

Social and biological factors in very early life influence dental caries levels later in life [4]. Studies confirm that low social class increases the risk of developing high levels of dental caries. Parents' low educational level and professional situation (employed/unemployed) also play an important role in the child/adolescent oral health status [4].

WHO recently has dedicated special attention on health-promoting programs applied in schools and emphasized more on oral health education as an important issue that should be developed among the population in order to decrease the prevalence of oral illnesses, namely dental caries and periodontal diseases, and most recently, oral cancer [5]. The necessity to develop primary prevention strategies is a reality in order to decrease oral cavity diseases [5].

Oral pain is a very common symptom of oral health conditions. It surely affects negatively an individual's daily life activities and social functioning [6]. The risk of development of oral diseases is strongly related to the lifestyle and daily habits. Poor oral health can have a considerable effect on children's performance in school, quality-of-life and their success in later life. Children who suffer from poor oral health are 12 times more likely to have more restricted-activity days including missing school than those who do not [5].

In 2008, the General Health Directory of Portugal (DGS-Portugal) presented the last nationwide study of the prevalence of oral diseases. In this study, it is shown that the decayed, missing and filled teeth index (DMFT index) among adolescents aged 12 and 13 years, was 1.48 and 3.04 respectively. The prevalence of dental caries increased with age and was also higher among the poorer socio-economic classes. This national study also revealed that only $63 \%$ of portuguese adolescents, aged 15 years old, referred to do tooth brushing more than once a day, only $25 \%$ use dental floss and $85 \%$ attended to a dental appointment in the last 12 months [7]. This study demonstrates the need for better oral health education among the adolescents and their family in order to improve the national oral health indicators. Other studies demonstrate high prevalence of dental caries among children and adolescents worldwide. A study developed by Dukic et al., in Zagreb, Croatia demonstrates a high prevalence of dental caries among schoolchildren which has become a major public health issue in this country and indicates the need for an extensive program of primary oral healthcare [8]. Traebert et al., conducted a study in the municipality of Santa Catarina, Brazil, and found that the prevalence of caries in the primary dentition in children aged 6 years was $60.9 \%$ in public schools, attended mostly by children with a lower socioeconomic status and $34.9 \%$ in private schools which had mostly children with a higher socioeconomic status [9]. In a study developed in Saudi Arabia, the national prevalence of dental caries and its severity among children was estimated to be approximately $80 \%$ for the primary dentition and $70 \%$ for children's permanent dentition [10].

Based on the above mentioned explanations the objective of this study was the assessment of the prevalence of oral health behaviors among a sample of portuguese adolescents and verify their association with socio-de- 
mographic variables in order to analyze the need of oral health education programmes among the studied community.

\section{Methods}

\subsection{Sample Study}

A non-probability convenience sampling of 447 adolescents aged between 12 and 18 years old, attending a public school in Sátão, Portugal, was enrolled in this epidemiological observational cross-sectional study that was carried out from September to December of 2012. The studied sample represents the entire school group of the area, and $88.6 \%$ of its pupils were enrolled in the study. Questionnaires without information about gender and age were excluded from the study as well as the adolescents whose parents did not sign the informed consent before data collection.

\subsection{Instruments and Variables in Study}

A self-administered questionnaire with questions about sociodemographic variables, social and daily habits and oral health behaviours was filled out by adolescents in the classroom. Sociodemographic variables such as gender (male/female), age, school grade at the moment of the study, residence area (living in a village near the town of Sátão was considered rural area and living in the town of Sátão was considered urban area), parents' educational level (choosing the higher educational level between father and mother) and father's professional situation (employed/unemployed) were determined. Oral health behaviours were assessed by questioning adolescents about their ideas on their own oral health, the frequency of tooth brushing per day, time spent tooth brushing (in minutes), period of the day that each adolescent tooth brushed, daily use of dental floss, having a dental appointment in the last 12 months and the reason of the last dental appointment, if he or she had experienced at least one episode of dental pain during their lives, if adolescents were afraid of going to the dentist, if they knew what was a fissure sealant and if their dentist had ever applied fissure sealants during a dental appointment and finally if they frequently consumed sugary beverages or soft drinks.

\subsection{Statistical Analysis}

Data analysis was carried out using SPSS for Windows (version 18.0). Prevalence was expressed in proportions and crude odds ratio (OR) with 95\% confidence intervals (CI) was used to measure the strength of association between variables. Proportions were compared by the Chi-square test and continuous variables by the KruskalWallis and Mann-Whitney tests. The significance level established the inferential statistics was $5 \%(\mathrm{p}<0.05)$. A multivariate analysis—-logistic regression—was applied for analysis of the association between variables.

\subsection{Legal and Ethical Procedures}

This research involving human data has been performed in accordance with the Declaration of Helsinki and was submitted and approved by the Ethics Committee of the Research Centre for Education, Technology and Health Studies of the Polytechnic Institute of Viseu, Portugal (CI\&DETS).

The information collected by the questionnaires was provided voluntarily and confidentially. The anonymity of the information collected was guaranteed by telling adolescents not to sign their names or write down any other form of identification in any part of the questionnaire. Data collection taken into account only considered the answers given by adolescents whose parents signed an informed consent that explained the objectives of the study. After collection, questionnaires were numbered, stored and processed by computer. The results do not make reference to adolescents' names or contain any information that may identify any of the participants.

\section{Results}

\subsection{Sample Characterization}

The final sample was composed by 447 adolescents, 38.3\% male gender and $61.7 \%$ female gender, all between the age of 12 and 19 years old, from a public school of Sátão, Portugal. When analyzing the parents' educational level, we verified that $4.3 \%$ had parents that only frequented school for less than the $4^{\text {th }}$ grade, $53.5 \%$ stayed in 
school from the $5^{\text {th }}$ to the $12^{\text {th }}$ grade and $15.0 \%$ proceeded to a higher degree after finishing the $12^{\text {th }}$ grade. A crowding index $\leq 1.0$ was obtained to $85.5 \%$ of adolescents, while only $4.5 \%$ presented a value $>1.0$, which indicates possible overcrowding at home. The analysis of the distribution of the sample by residence area, showed that the majority of the individuals lived in rural areas (65.3\% vs 34.7\%) (Table 1 ).

\subsection{Oral Health Behaviors}

In the studied sample, we verified that $13.3 \%$ of the adolescents consider having a very good oral health, $65.7 \%$ good oral health and $21.0 \%$ moderate/poor oral health. When assessing daily tooth brushing, 9.4\% tooth brush only once a day, $67.3 \%$ twice a day and $23.3 \%$ tooth brush 3 or more times a day. From those who have the daily oral hygiene habit of tooth brushing, only $27.1 \%$ tooth brush during 3 or more minutes each time. When assessing the prevalence of tooth brushing after getting up in the morning, after meals and before going to bed, we obtained the results presented in Table 2.

Table 1. Sample characterization.

\begin{tabular}{|c|c|c|c|c|c|c|}
\hline & \multicolumn{2}{|c|}{ Male } & \multicolumn{2}{|c|}{ Female } & \multicolumn{2}{|c|}{ Total } \\
\hline & $\mathrm{N}$ & $\%$ & $\mathrm{~N}$ & $\%$ & $\mathrm{~N}$ & $\%$ \\
\hline & 171 & 38.3 & 276 & 61.7 & 447 & 100.0 \\
\hline \multicolumn{7}{|l|}{ Age } \\
\hline 12 & 31 & 18.2 & 27 & 9.8 & 58 & 13.0 \\
\hline 13 & 29 & 17.0 & 38 & 13.8 & 67 & 15.0 \\
\hline 14 & 18 & 10.5 & 34 & 12.3 & 52 & 11.6 \\
\hline 15 & 28 & 16.4 & 27 & 9.8 & 55 & 12.3 \\
\hline 16 & 16 & 9.4 & 34 & 12.3 & 50 & 112 \\
\hline 17 & 16 & 9.4 & 29 & 10.5 & 45 & 10.1 \\
\hline 18 & 18 & 10.5 & 43 & 8.3 & 61 & 13.6 \\
\hline 19 & 15 & 1.8 & 44 & 16.0 & 59 & 13.0 \\
\hline \multicolumn{7}{|l|}{ Grade } \\
\hline 7 & 34 & 19.9 & 26 & 9.4 & 59 & 13.4 \\
\hline 8 & 26 & 15.2 & 38 & 13.8 & 64 & 14.3 \\
\hline 9 & 19 & 11.1 & 33 & 12.0 & 52 & 11.6 \\
\hline 10 & 30 & 17.5 & 38 & 13.8 & 68 & 15.2 \\
\hline 11 & 19 & 11.1 & 32 & 11.6 & 51 & 11.4 \\
\hline 12 & 43 & 25.2 & 109 & 39.5 & 152 & 34.0 \\
\hline \multicolumn{7}{|l|}{ Parents' educational level } \\
\hline$\leq 4$ grade & 3 & 2.0 & 16 & 6.9 & 19 & 4.3 \\
\hline 5 - 12 grade & 105 & 61.4 & 134 & 48.6 & 239 & 53.5 \\
\hline$>12$ grade & 30 & 17.5 & 37 & 13.4 & 67 & 15.0 \\
\hline Without information & 33 & 19.1 & 89 & 31.1 & 122 & 27.2 \\
\hline \multicolumn{7}{|l|}{ Crowding índex } \\
\hline$\leq 1.0$ & 135 & 78.9 & 247 & 89.5 & 382 & 85.5 \\
\hline$>1.0$ & 8 & 4.7 & 12 & 4.3 & 20 & 4.5 \\
\hline Without information & 28 & 16.4 & 17 & 6.2 & 45 & 10.0 \\
\hline \multicolumn{7}{|l|}{ Residential area } \\
\hline Rural & 100 & 58.5 & 192 & 69.6 & 292 & 65.3 \\
\hline Urban & 71 & 41.5 & 84 & 30.4 & 155 & 34.7 \\
\hline
\end{tabular}


Table 2. Prevalence of tooth brushing in different moments of the day.

\begin{tabular}{ccccc}
\hline & \multicolumn{2}{c}{ Yes } & \multicolumn{3}{c}{ No } \\
\cline { 2 - 5 } & $\mathrm{N}$ & $\%$ & $\mathrm{~N}$ & $\%$ \\
\hline After getting up from bed & 56 & $27.3 \%$ & 149 & $72.7 \%$ \\
After breakfast & 33 & $10.1 \%$ & 295 & $89.9 \%$ \\
After lunch & 51 & $36.4 \%$ & 89 & $63.6 \%$ \\
After snacks & 91 & $84.3 \%$ & 17 & $15.7 \%$ \\
After dinner & 55 & $24.1 \%$ & 173 & $75.8 \%$ \\
Before going to bed & 37 & $11.1 \%$ & 297 & $88.9 \%$ \\
\hline
\end{tabular}

When the adolescents were asked if they brushed also their tongue during oral hygiene, $83.2 \%$ refer brushing their teeth, not forgetting to brush the tongue, which corresponds to a complete process of brushing. Adolescents were also questioned about their oral hygiene learning process, and in this situation we verified that $41.7 \%$ refer that their dentist never taught them how to tooth brush, while $58.3 \%$ say that their dentist have, at least once, talked about the basic measures of daily oral hygiene.

When assessing the use of dental floss, our study shows that only 5.8\% use dental floss daily, while $33.9 \%$ refer using dental floss sometimes and $60.2 \%$ say that never use dental floss during their oral hygiene.

Dental appointments was another important variable analysed and our results demonstrate that $67.0 \%$ had a dental appointment in the last twelve months which demonstrates that a high prevalence of adolescents do not have a dental appointment at least twice a year. When assessing the main reason of the last dental appointment, 85\% refer having a routine dental appointment, $35.8 \%$ visited a dentist in the presence of dental pain and had a dental appointment in an emergency situation and $58.2 \%$ for dental caries treatment. Adolescent's fear of the dental appointment was present in only $15.3 \%$ of the participants of the study.

When questions about the application of fissure sealants were addressed, only $28.9 \%$ referred knowing what fissure sealants are and only $15.5 \%$ knew if their dentist had applied them in a past dental appointment. The prevalence of dental fear presented by the adolescents was $15.3 \%$, which can compromise the routine dental appointment that these adolescents should schedule at least twice a year. Finally, and after analysis of the variable referring to the consumption of sweet beverages and soft drinks, the prevalence among the adolescents was $92.5 \%$.

When associating oral health behaviors and socio-demographic variables we can verify that tooth brushing at least twice a day is more frequent among adolescents whose parent's have a higher level of education $\left(>9^{\text {th }}\right.$ grade, $\mathrm{OR}=1.12$, $(\mathrm{CI} 95 \%=0.54-2.32)$ ), with higher age $(>15$ years, $\mathrm{OR}=1.34, \mathrm{CI} 95 \%=(0.68-2.65))$ and among the female gender (female, OR $=3.65$, CI $95 \%=(1.85-7.18)$ ). However, significant statistical differences were only found among female and male gender (94.9\% vs 83.6\%, $\mathrm{p}<0.001$ ) (Table 3 ).

When associating the daily use of dental floss and socio-demographic variables we can verify that the use of dental floss is higher among adolescents whose parent's have a higher level of education ( $>9^{\text {th }}$ grade, $\mathrm{OR}=1.07$, CI $95 \%=(0.68-1.67))$, with higher age $(>15$ years, OR $=1.90$, CI $95 \%=(1.24-2.92))$, in female gender (female, OR $=2.03$, CI $95 \%=(1.35-3.05)$ ), live in urban areas (urban, OR $=1.25$, CI $95 \%=(0.81-1.92)$ ) and living in house with a higher crowding index $(>1, \mathrm{OR}=1.04$, CI $95 \%=(0.41-2.60))$. Significant statistical differences were found among gender $(46.0 \%$ vs $29.6 \%$, $\mathrm{p}<0.001)$ and age of the adolescent $(45.8 \%$ vs $32.9 \%, \mathrm{p}=$ 0.001) (Table 4).

Analyzing the association between socio-demographic variables and dental appointments in the last twelve months we verify significant statistical differences among dental appointments in the last twelve months and father's unemployment $(41.5 \%$ vs $68.1 \%, \mathrm{p}<0.001)$ and crowding index ( $55.0 \%$ vs $67.4 \%, \mathrm{p}=0.040$ ) (Table 5 ).

When associating dental pain in the last twelve months and socio-demographic variables we can verify that the prevalence of dental pain was higher among adolescents whose father was unemployed (unemployed, OR = 1.27, (CI 95\% = $0.65-2.5)$ ) and the female gender (female, OR $=2.21$, CI 95\% = $(1.44-3.40)$ ), having only registered significant statistical differences between genders, verifying a higher prevalence among the female gender $(39.5 \%$ vs $22.8 \%$, $\mathrm{p}<0.001)$.

When associating the consumption of soft drinks and socio-demographic variables we observe that the prevalence of consumption of these kind of sweet beverages was higher among adolescents that registered a higher 
Table 3. Prevalence of tooth brushing (per day) and the association with socio-demographic variables.

\begin{tabular}{|c|c|c|c|c|c|}
\hline \multirow{2}{*}{ Tooth brushing } & \multicolumn{2}{|c|}{$<2$ times a day } & \multicolumn{2}{|c|}{$\geq 2$ times a day } & \multirow{2}{*}{$\mathrm{p}$} \\
\hline & $\mathrm{N}$ & $\%$ & $\mathrm{~N}$ & $\%$ & \\
\hline \multicolumn{6}{|c|}{ Parents' educational level } \\
\hline$\geq 4$ grade & 2 & 10.5 & 17 & 89.5 & 0.503 \\
\hline 5 - 12 grade & 24 & 10.3 & 210 & 89.7 & \\
\hline$>12$ grade & 6 & 9.0 & 61 & 91.0 & \\
\hline \multicolumn{6}{|c|}{ Father's professional situation } \\
\hline Employed & 30 & 9.6 & 283 & 90.4 & 0.521 \\
\hline Unemployed & 4 & 10.3 & 35 & 89.7 & \\
\hline \multicolumn{6}{|l|}{ Gender } \\
\hline Male & 27 & 16.4 & 138 & 83.6 & $<0.001$ \\
\hline Female & 14 & 5.1 & 261 & 94.9 & \\
\hline \multicolumn{6}{|l|}{ Age } \\
\hline$\leq 15$ years & 23 & 10.3 & 200 & 89.7 & 0.252 \\
\hline$>15$ years & 15 & 7.9 & 175 & 92.1 & \\
\hline \multicolumn{6}{|l|}{ Residence area } \\
\hline Rural & 20 & 8.8 & 207 & 91.2 & 0.365 \\
\hline Urban & 14 & 10.4 & 120 & 89.6 & \\
\hline \multicolumn{6}{|l|}{ Crowding index } \\
\hline$\leq 1$ & 32 & 9.1 & 318 & 90.9 & 0.545 \\
\hline$>1$ & 2 & 11.8 & 15 & 88.2 & \\
\hline
\end{tabular}

Table 4. Prevalence of daily use of dental floss and the association with socio-demographic variables.

\begin{tabular}{|c|c|c|c|c|c|}
\hline \multirow{2}{*}{ Daily dental floss } & \multicolumn{2}{|c|}{ Yes } & \multicolumn{2}{|c|}{ No } & \multirow{2}{*}{$\mathrm{p}$} \\
\hline & $\mathrm{N}$ & $\%$ & $\mathrm{~N}$ & $\%$ & \\
\hline \multicolumn{6}{|c|}{ Parents' educational level } \\
\hline$\geq 4$ grade & 7 & 36.8 & 12 & 63.2 & 0.532 \\
\hline 5 - 12 grade & 87 & 36.6 & 151 & 63.4 & \\
\hline$>12$ grade & 27 & 40.9 & 39 & 59.1 & \\
\hline \multicolumn{6}{|c|}{ Father's professional situation } \\
\hline Employed & 122 & 38.7 & 193 & 61.3 & 0.211 \\
\hline Unemployed & 13 & 31.7 & 28 & 68.3 & \\
\hline \multicolumn{6}{|l|}{ Gender } \\
\hline Male & 50 & 29.6 & 119 & 70.4 & $<0.001$ \\
\hline Female & 127 & 46.0 & 149 & 54.0 & \\
\hline \multicolumn{6}{|l|}{ Age } \\
\hline$\leq 15$ years & 75 & 32.9 & 153 & 67.1 & 0.001 \\
\hline$>15$ years & 87 & 45.8 & 103 & 54.2 & \\
\hline \multicolumn{6}{|l|}{ Residence area } \\
\hline Rural & 84 & 36.7 & 45 & 63.3 & 0.192 \\
\hline Urban & 57 & 41.9 & 79 & 58.1 & \\
\hline \multicolumn{6}{|l|}{ Crowding index } \\
\hline$\leq 1$ & 137 & 39.1 & 213 & 60.9 & 0.664 \\
\hline$>1$ & 8 & 40.0 & 12 & 60.0 & \\
\hline
\end{tabular}


Table 5. Prevalence of dental appointments (last twelve months) and the association with socio-demographic variables.

\begin{tabular}{|c|c|c|c|c|c|}
\hline \multirow{2}{*}{$\begin{array}{l}\text { Dental appointment } \\
\text { (last twelve months) }\end{array}$} & \multicolumn{2}{|c|}{ No } & \multicolumn{2}{|c|}{ Yes } & \multirow{2}{*}{$\mathrm{p}$} \\
\hline & $\mathrm{N}$ & $\%$ & $\mathrm{~N}$ & $\%$ & \\
\hline \multicolumn{6}{|l|}{ Parents' educational level } \\
\hline$\geq 4$ grade & 5 & 26.3 & 14 & 73.7 & 0.163 \\
\hline 5 - 12 grade & 83 & 35.0 & 154 & 65.0 & \\
\hline$>12$ grade & 15 & 23.1 & 50 & 76.9 & \\
\hline \multicolumn{6}{|c|}{ Father's professional situation } \\
\hline Employed & 100 & 31.9 & 213 & 68.1 & $<0.001$ \\
\hline Unemployed & 24 & 58.5 & 17 & 41.5 & \\
\hline \multicolumn{6}{|l|}{ Gender } \\
\hline Male & 62 & 36.9 & 106 & 63.1 & 0.112 \\
\hline Female & 84 & 30.5 & 194 & 69.5 & \\
\hline \multicolumn{6}{|l|}{ Age } \\
\hline$\leq 15$ years & 75 & 33.7 & 150 & 66.7 & 0.532 \\
\hline$>15$ years & 65 & 34.0 & 126 & 66.0 & \\
\hline \multicolumn{6}{|l|}{ Residence area } \\
\hline Rural & 78 & 34.2 & 150 & 65.8 & 0.411 \\
\hline Urban & 48 & 35.6 & 87 & 64.4 & \\
\hline \multicolumn{6}{|l|}{ Crowding index } \\
\hline$\leq 1$ & 114 & 32.6 & 236 & 67.4 & 0.041 \\
\hline$>1$ & 9 & 45.0 & 11 & 55.0 & \\
\hline
\end{tabular}

crowding index $(>1, \mathrm{OR}=1.43$, CI $95 \%=(0.18-11.16))$ and lower among the other socio-demographic variables analyzed, having only registered significant statistical differences for age ( $\leq 15$ years, $97.8 \%$ vs $86.7 \%$, $\mathrm{p}$ $<0.001$ ) and residence area (rural, 93.8\% vs $88.2 \%, \mathrm{p}=0.040$ ).

After adjustment by non-conditional logistic regression for sociodemographic variables, and oral health behaviors, the findings of the present study demonstrate that the frequency of dental appointments is associated with the father's professional situation (unemployed) $(\mathrm{OR}=2.91,95 \% \mathrm{CI}=(1.39-6.10))$.

\section{Discussion}

The present study demonstrates that measures must be taken in order to improve oral health behaviors among Portuguese adolescents. The daily routine of tooth brushing is continuously being well established, but there is still a lack of comprehension of the importance of completing oral hygiene with other methods such as the use of dental floss and including also the routine dental appointment. There is still the need to improve some aspects related with oral hygiene habits, namely the time spent on brushing that should be at least during approximately three minutes and brush not only the teeth but also other structures of the oral cavity such as tongue, gums and palate in order to remove plaque that accumulates in these areas [11].

The study also reflects the relation between oral health behaviors and socio-demographic factors already referred in other studies that demonstrate that socio-economic and cultural aspects may influence the oral hygiene habits. The lack of information and knowledge about oral health behaviors and limited access to dental healthcare explain the association between the higher risk of oral diseases and lower socio-economic status [12]-[16].

Several studies also evidence that adolescents with lower socio-economic status have a higher risk of developing oral diseases, namely dental caries, which is also associated with worse oral hygiene habits and less frequency of routine dental appointments [17]-[19].

Correct oral hygiene habits are more frequent among the female gender and this study confirms this statement. Adolescents of the female gender are more careful with their health than male adolescents and this is mainly as- 
sociated with a higher care with their aesthetical presentation by the female gender [20]-[22].

The prevalence of daily use of dental floss was very low among this sample and when associating daily use of dental floss and socio-demographic variables we can verify in this study significant statistical differences found among gender and age, which is described in other studies [23]. A study developed by Pereira et al. also with a sample of portuguese adolescents, demonstrates that the prevalence of daily use of dental floss was only $4.4 \%$ [13].

More females and adolescents over 15 years old were more likely to report using dental floss. These results suggest the need of better oral health education among adolescents and teach them specifically the importance of the daily use of dental floss as a positive method in order to complete their daily oral hygiene. Many adolescents don't make routinely dental appointments at least twice a year as is recommended. Unfortunately, in many cases, a dental appointment is made only in a urgent/emergency situation, mostly because of dental pain as shown by the results presented in this study. This fact was demonstrated, in some studies, as being highly associated with socio-demographic variables such as level of education, residence area and financial and social income [6] [18] [24] [25]. A study developed by Santiago et al., demonstrates the association between neighbourhood and individual social capital with dental pain. In this study, we verified that a high proportion of adolescents do not have routine dental appointments and they only go to the dentist in a emergency situation of dental pain [26].

Unfortunately, in Portugal nowadays, we assist to an increase of unemployment that limits the access to medical and dental healthcare due to the economic and social crisis. In Portugal, the inequality access to oral healthcare among the population is evident. It is known the difficulty of access to oral healthcare by individuals socioeconomically disadvantaged. This situation occurs due to the fact that the vast majority of oral healthcare is being provided by the private sector, involving funds that not all people are able to support [27]. This is a major issue in Portugal and it is reflected in the results of this study that demonstrate this association as we can verify that adolescents whose father was unemployed in the moment of data collection and that registered a higher crowding index had a dental appointment less frequently and mostly visited a dentist only in a emergency situation of dental pain.

The lack of information about the importance and the need of a dental appointment should be a part of oral health education in order to decrease the fear of going to visit a dentist. Unfortunately, fear and anxiety when going to visit the dentist is a reality and it is still very common among children, adolescents, adults and even elders [28]. Also in this study, we verified a considerable prevalence of fear of going to visit a dentist, mostly among the younger adolescents and also among the female gender, that are, at the same time, the gender that goes more regularly to a dental appointment.

Another major risk factor related with the development of oral diseases is the consumption of sugary foods and drinks. In this study, we verified that a very high proportion of adolescents consume regularly sugary beverages or soft drinks. This proves the necessity of alerting the population, namely children/adolescents and their parents, for the negative effects of excessive sugar consumption on oral health [29].

Considering the results obtained in the present study, the need of strategies for oral health education is important and must be implemented effectively in order to improve the oral health knowledge and oral hygiene status of adolescents [30].

Oral health education is a major public health issue that must be taught to children and adolescents among their own family aggregate and school environment. Oral health promotion is very important in order to insure the application of primary prevention methods such as daily tooth brushing at least twice a day, daily use of dental floss and visiting a dentist regularly to prevent and detect oral diseases in a early stage. Oral health education is the first step in the prevention of oral diseases, in order to decrease socio-demographic differences and to give equal opportunities of oral health, promoting the measures necessary for the improvement of quality-of-life among the population [12] [31]-[33].

The oral health education should also cover food hygiene comprising the control of the consumption of cariogenic foods with a high content of carbohydrates which is fundamental to avoid the development of dental caries [21].

Another important issue that should be acknowledged in oral health education is the unnecessary fear of the dental appointment. Studies demonstrate that this is one of the main reasons for avoiding a visit to the dentist, especially among children and adolescents. A study developed by Murthy et al. demonstrated that dental fear was shown to be a significant determinant of clinical consequences of untreated dental caries [34].

In the present study we must have also in consideration its limitations. Data collection was accomplished by 
self-administered questionnaires to the adolescents, which may permit a higher risk of potential information bias, despite the sample analyzed. More epidemiological studies should be developed in the future, in different geographical regions of the country, in order to understand the prevalence and patterns of oral health behaviours among the portuguese population.

\section{Conclusions}

Community programs should be considered and developed in order to improve knowledge and behaviors related to the oral health of adolescents, giving special attention to the intervention of various health professionals, teachers and parents in the oral health education that should be transmitted to children and adolescents. Therefore, oral health education activities directed towards the prevention of risk factors for developing oral diseases should involve both parents and their children, because parental behavior is a significant predictor of children's oral health.

It is important to include in the oral health programs, not just children and adolescents, but also their parents in order to have the necessary knowledge on how to have good oral health habits and transmit that information and motivation to their children.

It is essential that, in a early stage, children acquire adequate oral hygiene habits, particularly about brushing their teeth at least twice a day with toothpaste, daily use of dental floss and the need to have regular dental appointments at least twice a year in order to treat as soon as possible oral diseases and apply primary prevention measures. These are essential basic oral health determinants that should be taught in oral health education.

\section{Acknowledgements}

The authors are deeply indebted to the researchers that participated in the development of this study and data collection phase: Prof. Odete Amaral, Prof. Claudia Chaves, Prof. Paula Nelas, Prof. Manuela Ferreira, Dr. Marco Baptista and Dr. Inês Coelho. We also thank the teachers and students of the School Group of Sátão, Portugal, for the participation and important contribution to this study.

\section{Funding}

This study was funded by the Fundação para a Ciência e Tecnologia and CI\&DETS (Portugal).

\section{Competing Interests}

The authors declare that they have no competing interests.

\section{References}

[1] World Health Organization (2003) The World Oral Health Report 2003. Continuous Improvement of Oral Health in the 21st Century-The Approach of the WHO Global Oral Health Programme. WHO, Geneva.

[2] Bastos, J., Gigante, D., Peres, K. and Nedel, F. (2007) Social Determinants of Odontalgia in Epidemiological Studies: Theoretical Review and Proposed Conceptual Model. Ciência \& Saúde Coletiva, 12, 1611-1621. http://dx.doi.org/10.1590/S1413-81232007000600022

[3] Petersen, P., Kjoller, M., Christensen, L. and Krustrup, U. (2004) Changing Dentate Status of Adults, Use of Dental Health Services, and Achievement of National Dental Health Goals in Denmark by the Year 2000. Journal of Public Health Dentistry, 64, 127-135. http://dx.doi.org/10.1111/j.1752-7325.2004.tb02742.x

[4] Peres, M., Latorre, M., Sheiham, A., Peres, K., Barros, F., Hernandez, P. and Victora, C. (2005) Social and Biological Early Life Influences on Severity of Dental Caries in Children Aged 6 Years. Community Dentistry and Oral Epidemiology, 33, 53-63. http://dx.doi.org/10.1111/j.1600-0528.2004.00197.x

[5] World Health Organization (2003) WHO Information Series on School-Health. Oral Health Promotion: An Essential Element of Health-Promoting Schools. Document 11. WHO, Geneva.

[6] Ravaghi, V., Quinonez, C. and Allison, P. (2013) Oral Pain and Its Covariates: Findings of a Canadian PopulationBased Study. Journal of the Canadian Dental Association, 79, d3.

[7] General Health Directory (2008) National Study of Prevalences of Oral Diseases. GHD, Lisbon.

[8] Dukic, W., Delija, B. and Dukic, O. (2011) Caries Prevalence among Schoolchildren in Zagreb, Croatia. Croatian Medical Journal, 52, 665-671. http://dx.doi.org/10.3325/cmj.2011.52.665 
[9] Traebert, J., Peres, M., Galesso, E., Zabot, N. and Marcenes, W. (2001) Prevalence and Severity of Dental Caries among Schoolchildren Aged Six and Twelve. Revista de Saúde Pública, 35, 283-288. http://dx.doi.org/10.1590/S0034-89102001000300011

[10] Al Agili, D. (2013) A Systematic Review of Population-Based Dental Caries Studies among Children in Saudi Arabia. Saudi Dental Journal, 25, 3-11. http://dx.doi.org/10.1016/j.sdentj.2012.10.002

[11] Daniel, S., Harfst, S., Wilder, R., Francis, B. and Mitchell, S. (2008) Mosby’s Dental Hygiene: Concepts, Cases and Competencies. 2nd Edition, Mosby Elvesier, St Louis.

[12] Honkala, E., Honkala, S., Rimpela, A. and Rimpela, M. (2001) The Trend and Risk Factors of Perceived Toothache among Finnish Adolescentes from 1977 to 1997. Journal of Dental Research, 80, 1823-1827. http://dx.doi.org/10.1177/00220345010800091001

[13] Pereira, C., Veiga, N., Amaral, O. and Pereira, J. (2013) Oral Health Behaviors in a Sample of Portuguese Adolescents. Revista de Saúde Pública, 31, 158-165. http://dx.doi.org/10.1016/j.rpsp.2013.03.002

[14] Poutanen, R., Lahti, S., Seppa, L., Tolvanen, M. and Hausen, H. (2007) Oral Health-Related Knowledge, Attitudes, Behavior, and Family Characteristics among Finnish Schoolchildren with and without Active Initial Caries Lesion. Acta Odontologica Scandinavica, 65, 87-96. http://dx.doi.org/10.1080/00016350601058077

[15] Schwarz, E. (2006) Access to Oral Health Care-An Australian Perspective. Community Dentistry and Oral Epidemiology, 34, 225-231. http://dx.doi.org/10.1111/j.1600-0528.2006.00301.x

[16] Sistani, M., Yazdani, R., Virtanen, J., Pakdaman, A. and Murtomaa, H. (2013) Determinants of Oral Health: Does Oral Health Literacy Matter? ISRN Dentistry, 2013, 1-6. http://dx.doi.org/10.1155/2013/249591

[17] Julihn, A., Agholme, M., Grindefjord, M. and Modéer, T. (2006) Risk Factors and Risk Indicators Associated with High Caries Experience in Swedish 19-Year-Olds. Acta Odontologica Scandinavica, 64, 267-273. http://dx.doi.org/10.1080/00016350600613534

[18] Nicolau, B., Marcenes, W., Bartley, M. and Sheiham, A. (2005) Associations between Socio-Economic Circumstances at Two Stages of Life and Adolescents' Oral Health Status. Journal of Public Health Dentistry, 65, 14-20. http://dx.doi.org/10.1111/j.1752-7325.2005.tb02782.x

[19] Timis, T. and Danila, I. (2005) Socioeconomic Status and Oral Health. Journal of Preventive Medicine, 13, $116-121$.

[20] Locker, D. (2000) Deprivation and Oral Health: A Review. Community Dentistry and Oral Epidemiology, 28, $161-169$. http://dx.doi.org/10.1034/j.1600-0528.2000.280301.x

[21] Ostberg, A., Halling, A. and Lindblad, U. (1999) Gender Differences in Knowledge, Attitude, Bahavior and Perceived Oral Health among Adolescents. Acta Odontologica Scandinavica, 57, 231-236. http://dx.doi.org/10.1080/000163599428832

[22] Peres, M., Peres, K., Barros, A. and Victoria, C. (2007) The Relation between Family Socioeconomic Trajectories from Childhood to Adolescence and Dental Caries and Associated Oral Behaviors. Journal of Epidemiology and Community Health, 61, 141-145. http://dx.doi.org/10.1136/jech.2005.044818

[23] Folayan, M., Khami, M., Folaranmi, N., Popoola, B., Sofola, O., Ligali, T. and Orenuga, O. (2013) Determinants of Preventive Oral Health Behavior among Senior Dental Students in Nigeria. BMC Oral Health, 13, 28. http://dx.doi.org/10.1186/1472-6831-13-28

[24] Bastos, R., Carvalho, E., Xavier, A., Caldana, M., Bastos, J. and Lauris, J. (2012) Dental Caries Related to Quality if Life in Two Brazilian Adolescente Groups: A Cross-Sectional Randomised Study. International Dental Journal, 62, 137-143. http://dx.doi.org/10.1111/j.1875-595X.2011.00105.x

[25] Petersen, P., Jiang, H., Peng, B., Tai, B. and Bian, Z. (2008) Oral and General Health Behaviors among Chinese Urban Adolescents. Community Dentistry and Oral Epidemiology, 36, 76-84.

[26] Santiago, B., Valença, A. and Vettore, M. (2013) Social Capital and Dental Pain in Brazilian Northeast: A Multilevel Cross-Sectional Study. BMC Oral Health, 13, 2. http://dx.doi.org/10.1186/1472-6831-13-2

[27] Almeida, C., Petersen, P., André, S. and Toscano, A. (2003) Changing Oral Health Status of 6- and 12-Year-Old Schoolchildren in Portugal. Community Dentistry and Oral Epidemiology, 20, 211-216.

[28] Syed, S., Bilal, S., Dawani, N. and Rizvi, K. (2013) Dental Anxiety among Adult Patients and Its Correlation with Self-Assessed Dental Status and Treatment Needs. Journal of Pakistan Medical Association, 63, 614-618.

[29] Touger-Decker, R. and Loveren, C. (2003) Sugars and Dental Caries. The American Journal of Clinical Nutrition, 78, 881S-892S.

[30] Haleem, A., Siddiqui, M. and Khan, A. (2012) School-Based Strategies for Oral Health Education of Adolescents-A Cluster Randomized Controlled Trial. BMC Oral Health, 12, 54. http://dx.doi.org/10.1186/1472-6831-12-54

[31] Okullo, I., Astrom, A. and Haugejorden, O. (2004) Influence of Perceived Provider Performance on Satisfaction with Oral Health Care among Adolescents. Community Dentistry and Oral Epidemiology, 32, 447-455. 
http://dx.doi.org/10.1111/j.1600-0528.2004.00183.x

[32] Qiu, R., Wong, M., Lo, E. and Lin, H. (2013) Relationship between Children’s Oral Health-Related Behaviors and Their Caregiver's Sense of Coherence. BMC Public Health, 13, 239. http://dx.doi.org/10.1186/1471-2458-13-239

[33] Yiu, C. and King, N. (2011) An Overview of Dental Caries-Preventive Approaches for Children. Hong Kong Dental Journal, 8, 29-39.

[34] Murthy, A., Pramila, M. and Ranganath, S. (2014) Prevalence of Clinical Consequences of Untreated Dental Caries and Its Relation to Dental Fear among 12-15-Year-Old Schoolchildren in Bangalore City, India. European Archives of Paediatric Dentistry, 15, 45-49. http://dx.doi.org/10.1007/s40368-013-0064-1 
Scientific Research Publishing (SCIRP) is one of the largest Open Access journal publishers. It is currently publishing more than 200 open access, online, peer-reviewed journals covering a wide range of academic disciplines. SCIRP serves the worldwide academic communities and contributes to the progress and application of science with its publication.

Other selected journals from SCIRP are listed as below. Submit your manuscript to us via either submit@scirp.org or Online Submission Portal.
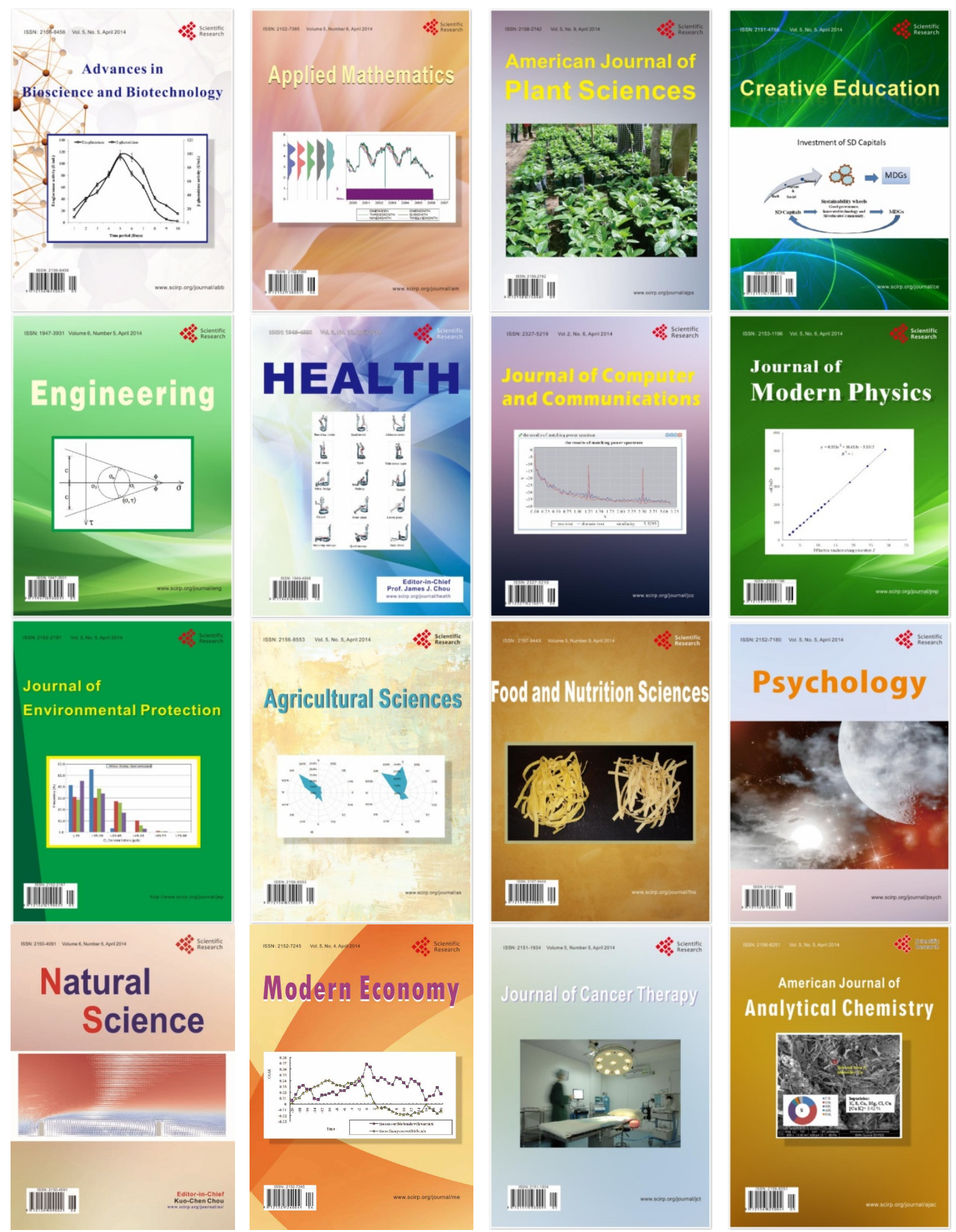